\title{
AngioVac: The first in Poland percutaneous solid thrombus aspiration from the right atrium
}

\author{
Mateusz Puślecki ${ }^{1}$ 2*, Sebastian Stefaniak ${ }^{2 *}$, Sławomir Katarzyński², Aneta Klotzka³, Piotr Buczkowski², \\ Małgorzata Ładzińska², Maciej Walczak², Joanna Stanisławiak-Rudowicz' ${ }^{4}$ Bartłomiej Perek², Maciej Lesiak ${ }^{3}$, \\ Marek Jemielity ${ }^{2}$, Marek Grygier ${ }^{3}$
}

'Department of Medical Rescue, Poznan University of Medical Sciences, Poznań, Poland

2Department of Cardiac Surgery and Transplantology, Poznan University of Medical Sciences, Poznań, Poland

${ }^{3} 1^{\text {st }}$ Department of Cardiology, Poznan University of Medical Sciences, Poznań, Poland

${ }^{4}$ Department of Oncological Gynecology, Poznan University of Medical Sciences, Poznań, Poland

*Both authors equally contributed to the study

Correspondence to: Mateusz Puślecki, MD, PhD, Department of Medical Rescue, Poznan University of Medical Sciences,

Długa 1/2, 61-848 Poznań, Poland,

phone: +48 618549 233, e-mail: mateuszpuslecki@o2.pl Copyright by the Author(s), 2022 DOI: 10.33963/KP.a2021.0128

\section{Received:}

September 3, 2021

Accepted:

October 12, 2021

Early publication date: October 13, 2021
The AngioVac system (AngioDynamics, Latham, NY, USA) is a novel method for the percutaneous removal of pathological masses, such as tumors or thrombi from the right atrium (RA), and vegetations from pacemaker leads or the tricuspid valve. This device was dedicated initially to aspirate thrombi from the central venous system. Moreover, rare applications in the arterial vessels have also been described [1-4]. The patient may remain asymptomatic in the event of incidental findings or develop symptoms of pulmonary embolism in the case of a large thrombus of the venous system. Other origins may be bacterial or neoplastic.

This system that consists of a large (22 F) bore catheter with an expandable funnel-shaped distal tip is delivered through a $26 \mathrm{Fr}$ sheet (Figure 1A, B). Owing to con- nection to an extracorporeal circuit (ECC), this device enables not only the removal of intravascular thrombi but also the infusion of the filtrated blood back into the systemic circulation.

Herein, we present a successful removal of solid thrombus from the RA using the AngioVac system that, to our knowledge, was performed for the first time in Poland.

A 44-year-old female was referred to our center as a potential candidate for the AngioVac system procedure. The referral was preceded by transthoracic echocardiography and unsuccessful unfractionated heparin treatment. The solid mass attached to the free wall of RA was visualized in close proximity to the tip of the port catheter (Figure 1C, D). Because of cachexia and the initial diagnosis of ovarian carcinoma in the FIGO Illc stage, the

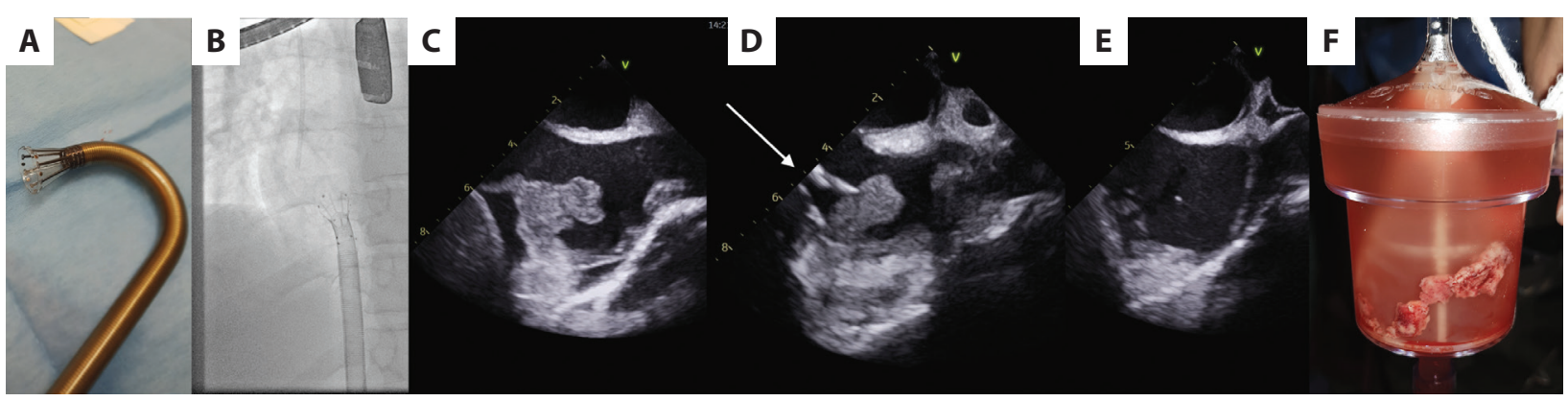

Figure 1. A. The AngioVac system with a 180-degree catheter. B. Fluoroscopy - AngioVac in the RA. C. TEE RA - thrombus mass. D. TEE RA - AngioVac Suction tip (the right arrow) near the thrombus. E. TEE RA - view after the procedure. F. The AngioVac system filter with the aspirated thrombus

Abbreviations: RA, right atrium; TEE, transesophageal echocardiography 
patient was disqualified from cardiac surgical intervention. Moreover, the removal of the right atrial pathological mass was a mandatory condition to continue chemotherapy and parenteral nutrition.

After the percutaneous insertion (modo Seldinger) of an Edwards $18 \mathrm{Fr}$ reinfusion cannula to the left femoral vein and the GORE Flex $26 \mathrm{Fr}$ sheet to the right one, the AngioVac system was inserted into the RA over the stiff wire. The anticoagulant treatment included heparinization in a dose of 100 units $/ \mathrm{kg}$. Under transesophageal echocardiography and fluoroscopic guidance, the device tip was placed near the thrombus (Figure 1B-D). ECC primed with saline and equipped with a centrifugal pump (RotaFlow, Getinge, Rastatt, Germany) was connected and then started with an initial speed of $500 \mathrm{rpm}$ (rotations per minute). After 3000 rpm was achieved, successful aspiration was performed. The transesophageal echocardiography examination confirmed the complete removal of the pathological mass (Figure 1E). After the full blood reinfusion, the material was visualized in the filter chamber (Figure 1F). The total procedure time was 1 hour, and the perfusion time was 15 minutes. The patient, after one day of monitoring and control transthoracic echocardiography, was discharged for further treatment.

So far, the RAPID registry enrolled the largest patient group ( $n=234$ from 21 centers). Among them, masses were found most often in the right heart (48.3\%), followed by caval veins (35.9\%), and on the catheter (8.5\%). Reported treatment success, defined as removal of over $70 \%$ of the clot, was achieved in $73.6 \%$ of caval thrombi, $58.5 \%$ of right heart mass, and $60 \%$ of catheter-related thrombi. Three deaths were reported, and 36 (13.2\%) procedure-related adverse events such as hemorrhage, distal embolization, arrhythmias, and cardiovascular perforations [5].
The limitation of this procedure is the obligatory use of a hybrid room and the involvement of a team familiar with perfusion techniques. Additionally, the costs of the ECC circuit and the suction cannula are high, but the minimally invasive design should justify them.

\section{Article information}

Conflict of interest: None declared.

Open access: This article is available in open access under Creative Common Attribution-Non-Commercial-No Derivatives 4.0 International (CC BY-NC-ND 4.0) license, allowing to download articles and share them with others as long as they credit the authors and the publisher, but without permission to change them in any way or use them commercially. For commercial use, please contact the journal office at kardiologiapolska@ptkardio.pl.

\section{REFERENCES}

1. Resnick $S A, O^{\prime}$ Brien $D$, Strain $D$, et al. Single-center experience using AngioVac with extracorporeal bypass for mechanical thrombectomy of atrial and central vein thrombi. J Vasc Interv Radiol. 2016; 27(5): 723-729. e1, doi: 10.1016/j.jvir.2016.02.009, indexed in Pubmed: 27106646.

2. Moriarty JM, Al-Hakim R, Bansal A, et al. Removal of caval and right atrial thrombi and masses using the AngioVac device: initial operative experience. J Vasc Interv Radiol. 2016; 27(10): 1584-1591, doi: 10.1016/j. jvir.2016.03.045, indexed in Pubmed: 27282218.

3. Donaldson CW, Baker JN, Narayan RL, et al. Thrombectomy using suction filtration and veno-venous bypass: single center experience with a novel device. Catheter Cardiovasc Interv. 2015; 86(2): E81-E87, doi: 10.1002/ccd.25583, indexed in Pubmed: 24975395.

4. Urbanowicz T, Araszkiewicz A, Marcinkowski P, et al. Inferior vena cava thrombus after veno-arterial ECMO therapy treated with mechanical thrombectomy in an LVAD patient. Kardiol Pol. 2021 [Epub ahead of print], doi: 10.33963/KP.a2021.0083, indexed in Pubmed: 34392512.

5. Moriarty JM, Rueda V, Liao $M$, et al. Endovascular removal of thrombus and right heart masses using the AngioVac system: results of 234 patients from the prospective, multicenter registry of angiovac procedures in detail (RAPID). JVasc Interv Radiol. 2021; 32(4): 549-557.e3, doi: 10.1016/j. jvir.2020.09.012, indexed in Pubmed: 33526346. 